\title{
Teacher Training in Secondary Education of Greece- A General Approach
}

\author{
Kalathaki Maria (Corresponding Author) \\ School Advisor for Science Teachers of West Crete \\ Director of the Regional Training Center of Heraklion, Crete, Greece \\ E-mail: kalathakimaria.edu@gmail.com
}

Received: March 8, 2018

doi:10.5296/jet.v5i2.13048
Accepted: April 4, 2018

Published: April 23, 2018

\begin{abstract}
Teacher Education and Training became more organized and targeted, treated by the Greek State, in the last half of the previous century. The Low 1566/1985 introduced firstly mandatory forms of training for teachers of Primary and Secondary Education which could carrying out by various organizations and Bodies, of many specialties and forms, in many places, with variety of content, methodologies and trainers. With this law, the Schools of Training for Primary and Secondary Teachers were initially established to offer yearly training to the teachers in scientific, didactic and pedagogical issues.

In the last 25 years, the 16 Regional Training Centers had the duty to download and decentralize the educational policies to the regions of Greece, to the newly appointed and permanent teachers. According to the Presidential Decree 250/1992, the Ministry of National Education and Religious Affairs may assign to the Pedagogical Institute or to a research institution the evaluation of the training work of the Regional Training Centers, at national level. The results of surveys on the efficiency of the training programs and the satisfaction of the Trainers have not published and discussed thoroughly. In the last 5 years, since the Ministry of Education has applied only three short-term Seminars guided, centrally designed and directed, less than 1000 School Advisors have shouldered the full weight of the Primary and Secondary teachers' training all over the Country, those the abolishment has been announced, without any evaluation report for their work.
\end{abstract}

Keywords: teacher training, Secondary Education, training programs

\section{Introduction}

The economic crisis was not a simple single hit that allows us to continue to operate as usual. The challenges that European Union faces are greater than before the recession, and there is limited space for maneuver, since the rest of the world is not stagnant. The strengthened role of the G-20 has demonstrated the growing economic and political power of emerging economies (Europe 2020, 2010). Additional European policy's objectives include the defense 
of human rights and democracy, the promotion of gender equality and addressing environmental and climate challenges. It is the largest development sponsor in the world (EC, 2009; EC, 2010). The EU's 'Agenda for Change' establishes the promotion of human rights, democracy, the rule of law and good governance and sustainable and inclusive development as the two main pillars of development policy. Three priorities was central to the Europe 2020 strategy, which mutually reinforce and shape the image of the social market economy for $21 \mathrm{st}$ century Europe: a. Smart growth - with the development of a knowledge and economy based on innovation, b. Sustainable development - by promoting more resource-efficient, greener and more competitive economy, c. Inclusive growth - by fostering a high-employment economy that ensures economic, social and territorial cohesion (EP, 2017). In this general strategic European framework, the members state have to develop their developmental policy, and through the educational and training organizations to prepare the students-the future citizens.

European Commission is launching the Digital Skills and Jobs Coalition to develop a large digital talent pool and ensure that individuals and the labor force in Europe are equipped with adequate digital skills. The Commission will support the sharing of best practices in this area among Member States and stakeholders through cooperation and mobility opportunities. Particular attention will be given to innovation in pedagogy. This will include supporting flexible curricula, promoting interdisciplinary and collaborative approaches within institutions, and supporting professional development to enhance innovative teaching practice, including ways of using and bringing digital tools into the classroom and stimulating entrepreneurial mindsets (COM-6, 2016).

EU believes that, through education and training in transversal and entrepreneurial skills, young people will be better equipped to compete for jobs, become self-employed and contribute to the innovative and competitive capability of an employer organization (LEC, 2000). Entrepreneurship is not solely about business creation, but also about setting the right environment for the development of a skilled, innovative, entrepreneurial workforce able to anticipate change and face challenges (PDECP, 2015). Many surveys recommend increasing the links among schools, business, industry and commerce. These links can be supported by the admission of a new position in all Secondary schools and colleges of industrial liaison and careers advisory offices to provide project support, external contacts and links to facilitate the development of authentic scenarios for skills development, business gaming and startups, and company entrepreneurial skills (Chell, 2015). Preparing for the post-2010 Europeans' era, the 'Education and Training 2010' work program provides practical support for the reform of the education and training systems of the Member States. Since the launch of the program in 2002, significant progress has been made but reforms in education and training need time to bear fruit. Major challenges persist, new challenges have arisen. This work, including cooperation under the Bologna and Copenhagen processes, continuing and increasing effectiveness, has to play crucial role in education and training, in the employment and development strategy of the European Union and the state members (EU, 2008).

Teachers have the responsibility in the new and demanded society for developing new knowledge, skills and competences within a framework of autonomous lifelong learning, where the students, as adult citizens, will continue to be concerned about their practice in a systematic 
research way. Teachers, in a rapidly changing world ought to incorporate in their teaching the results of the teaching and academic research, evaluate their effectiveness and modify their teaching strategies accordingly to their own training needs and the demands of their professional capability (SEC, 2007).

In Greece, in the continuously reforming of the educational system by the governments that took over the power in the last decades, new lows were created and semi-applied in the fields of School Education and Teachers' Training. In every government change, a new law created for the executives' selection (Directors, School Advisors, Heads) in Primary and Secondary Education but not for the evaluation of the work that they offered. So, there is not sufficient evidence to get conclusions and proposals for the training needs of the educational personnel of schools. Also, as there is no evaluation for the teachers in schools, there is no data about the effectiveness and the educational demands of the curricula.

Additionally, the economic crisis has dramatically restrict the expenses for the students' education by the families, the local authorities and the Government. In order, the students of the last class of Lyceums to participate successfully to the Pan-Hellenic Exams for the entrance to the University, many of them receive private lessons, in many times quite costly. Since, the changes in the training landscape are connected to the educational reforming of schools, this period is in progress the reconstruction of the School Education, following that of Higher Education. The Low 1566/1985 introduced mandatory forms of training for teachers of Primary and Secondary Education which could carrying out by various organizations and Bodies, of many specialties and forms, in many places, with variety of content, methodologies and trainers. The gaps in teachers' knowledge, the ever-changing requirements of school curricula, and the tendency to broaden the teacher's role, formed the basis for the provision and organization of the various training programs that addressed to the Secondary Teachers.

The duty of teachers' training in Greece undertook the Regional Training Centers (RTCs) which established with the low 2009/1992. In the last 25 years, the 16 Regional Training Centers (RTCs) had the mission to download and decentralize the educational policies to the regions of Greece, to the newly appointed and permanent teachers. They offered Training to thousands of Primary and Secondary Teachers with many Programs which designed by the Greek Ministry of Education and applied regionally.

According to the article 14 of the Presidential Degree 250/1992, the Ministry of National Education and Religious Affairs exercises general supervision over the operation of the RTCs and, within this competence, calls twice a year at a joint meeting the Directors of the RTCs and the representatives of the Pedagogical Institute in Athens or at the headquarters of any RTC, to identify general guidelines for the whole training project on the basis of identified needs, to coordinate the relevant activities and to determine the way in which each of the above actors participates in the realization of the program. Representatives of higher education and training institutions may also be invited to this meeting. 


\section{Method}

The basic question, which composed the main purpose of the research, was the investigation of the training that Secondary Teachers have received in the last 25 years. The active teacher population in Secondary Education, in Greece, graduated before 15-40 years and, in general terms, received limited training in organized and focusing way in the last 25 years. It is interesting to find out in national level, what training possibilities offered to them, since in local level, the variety and quantity of fragmented training seminars was large. Thus, it is impossible, with this limited extent and research requirements, to retrieve findings in extent and in depth. The results of this primitive research, which is presenting in this paper, can be exploited into design a future survey with the same, and more, research queries.

For the approach and development of the topic, literature of European Union's documents had been sought, mainly to those are referred to the targets and suggestions of the educational policy of schools and teachers, and the new directions and visions for the youth. Also, there was studied archival material of the teachers' training programs in Greece, where data listed and synthesized to give a more complete and unified picture of the situation in teacher training in Europe and, more specifically, in Greece.

In this qualitative research, a content analysis carried out in the official documents of European Union and Greek Ministry of Education that referred to strategies with guidelines and frameworks for the professional development of teachers and, widely, the future European citizens. The research categories, which correspond to the research objects, were set from the beginning of the research. Then, as the reading of the documents was in progress, the findings were registered in the pre-existing categories (Bell, 1997; Bird, 1990). Then, by the synthesis of the isolated sentences, resulted the findings in each category and conclusions were drawn. It was used the sentence as recording unit, since the word was making the inquiry very complex, without concentrated and clear correlation to the research object. During the critical reading of the documents, referring notes to the content were kept divided in the research categories, with comments and interpretations, in a kind of dialogue with the document.

The bibliographic overview became as general reference, after collecting and evaluating the information about the training programs which gathered from the relevant archive material. As the availability of statistics was limited, a relatively small number of documents was examined in a structured way, where, their gradual selection, and the analysis of the first, affected the following (Dimitropoulos, 1999). The findings introduced in the following categories: 1. From The Past... 1.1 Historical Stations in Teachers' Training, 1.2 Educational Reforms and Teacher Training, 1.3 Programs for Teachers Training, 1.3.1 Teacher Training by the Office of Secondary Education, 1.3.2 Teacher Training in the Regional Training Centers (RTCs), 1.3.3 Environmental Education and Education for the Sustainable Development, 1.4 Assessment of Teachers' Training in Greece, 2. For A Sustainable Future..., 2.1 The Cultivation of Creativity and Innovation, 2.2 Entrepreneurship in Education. 


\section{Results and Discussion}

\subsection{From The Past...}

\subsubsection{Historical Stations in Teachers' Training}

In Greece, in nineties, Teacher Education and Training started to be more organized and targeted, treated by the Greek State. Training Seminars, Programs and activities varied in numbers, topics and specialties of trainers and trainees, funded by the Government Budget.

The establishment of the Schools for the in-service Teachers Training in Primary and Secondary Education, called SELME and SELDE, was the first well organized effort with PanHellenic range (Presidential Degree 255/79). In these Schools, the teachers attended courses in pedagogic and didactic subjects in yearly base, having theoretical and practical exercise. In order teachers to have full morning horary training, they were replacing from their school positions. Replacement of teachers attending training courses is often a problem, as it had recorded also in Eurydice research (ED, 1995). SELME and SELDE ceased to exist from 1 July 1992, replacing by the Regional Training Centers (RTCs). Law 1268/82 established the Pedagogical Departments for Basic Education of Teachers of Primary Education which offer also post-graduate studies. With Law 1566/85 established the Regional Training Centers (RTCs) to undertake the training of the Teachers and re-established the Pedagogical Institute (PI). The Low 1566/1985 proposed compulsory forms of training for teachers, the 'Introductory' Training for newly appointed teachers of Primary and Secondary Education, the 'Yearly' for those have completed five years in-service with the aim to inform them about scientific and educational developments, the 'Periodic' Training when curricula change, and 'Other' type in regional and Pan-Hellenic level.

In Europe, the years between 1975 and 1985 was two major trends in the development of teacher training (Neave, 1990 in ED, 1995). It became necessary to consolidate the reforms undertaken earlier and to reassess educational priorities in the light of the increasing rate of technological and other changes in society. At the same time, education appeared essential to economic development and the appearance of a new critical dimension led to the birth of what became known as continuing education and Lifelong Learning. Some European Countries attempted to improve interaction between the world of education and society at large by encouraging relations with business firms, bringing the education and economic systems closer together, encouraging the study of the economic and social factors which influence young people's behavior and facilitating adaptation to social and cultural changes (ED, 1995). The offered training courses were about curricula and teaching methods, school organization and management, educational and psychological questions, sociological issues and areas of innovation with a variety in specialties of Trainers.

The Law 2009/1992 and the Presidential Degree 250/1992 defined the mission and the methodology of the training work in RTCs. In the 25 years of the RTCs' operation, changes took place in their structure, administration and training programs, depending on the demands of the training periods.

In the same period, PATES, SELETE, Schools which transformed into School of Pedagogical 
and Technological Education (ASPAITE) offer pedagogical and didactic specification to graduated students of non-teaching schools. Since September 2017, the Ministry of Education aimed in upgrading the School of Pedagogical and Technological Education (ASPAITE) and its contribution to a nationwide training system for teachers.

Law 2966/2002 established the Organization for the Training of Teachers (OEPEK). Later, OEPEK, PI, KEE, IPODE were merged into the Institute of Educational Policy (IEP) (Law 3966/2011).

In our days, RTCs, the Institute of Computer \& Publishing Technology 'ITYE Diofantos', the School Advisors and the Local Support Educational Structures offer Training opportunities to the local school staff, along with Postgraduate Curricula of Higher Education Institutions. There are many different educational structures of formal Education that materialize training seminars and programs, in local level, under the umbrella of the Regional Administrations of Primary and Secondary Education and the Administrations of Primary \& Secondary Education, such are the Science Laboratory Centres (EKFE), the Centre for Environmental Education (KPE), the Different Diagnosis, Diagnosis and Support Centre for Special Educational Needs (KEDDY), the Advising Stations for Youth (SSN), and the Centre for Advising and Orientation (KESYP). Specifically, Training in New Technologies in Education (a and b Level) has been undertaken by the Institute of Computer \& Publishing Technology (ITYE 'Diofantos') with other public and private Centers for Advising Training (KSE).

In the last 5 years, since the Ministry of Education has applied only three short-term Seminars, that were centrally designed and directed, the School Advisors of Primary and Secondary Education, less than 1000 in total number in Greece, had shouldered the full weight of the Primary and Secondary teachers' training, in all over the Country. They organized a large number of seminars, workshops, training visits and discussions in schools, etc., and in collaboration with scientists, Bodies, Authorities, Universities, Institutes, and Schools they kept upgrading the didactic and pedagogy in school education, in their regions of duty. With the schools advisors, the Ministry of Education downloaded all the attempted changes in the framework of educational reforms, by all the governments since 2002, when they established. In these optional, and not compulsory seminars, many teachers-volunteers, with variety of specialties, offered knowledge, wisdom and organizational support, but the response from the trainees was limited.

\subsubsection{Educational Reforms and Teacher Training}

In the continuously reforming of the educational system in Greece during the last half of previous century, many new lows were created for the executives' selection (Directors of the Educational Administrations, the School Directors, the School Advisors, the Heads of the local educational support structures, etc.) but few referred to the teachers' and executives' evaluation. Since a limited evaluation allowed to be applied on the offered educational work in schools, due to the reactions of the teachers' trade unionists and teacher associations, there is not adequate data to be drawn secure conclusions and formulated proposals about the topics of the training programs in accordance to the each time governmental policies. Also, as there is no evaluation for the teachers in schools, there is no data about the effectiveness of the curricula, 
the teaching methodology, and the educational and training demands. Additionally, the economic crisis has dramatically restrict the expenses for the school education of the government, the families and the local authorities, a reality that generates frustration and inability to school communities to respond to the challenges they face and ensure a sustainable future for their members.

As the framework of the Workshop, co-organized by the RTC of Piraeus and University of Peloponnese, at the Ionian School of Piraeus, in December 2017, the reform efforts of the last governments of Greece do not took place in a laboratory (in vitro) but in a rich social and educational context with great complexity, and for this required good planning, meaningful dialogue, agreement to a common issues with stakeholders, pilot implementation and appropriate support in order changes to be successful (HM-PL, 2017). With the cooperation of all three levels of Education, each teaching intervention will highlight scientific theories, views and constructions with open source curricula in content, methodology, with participants who will be both trainers and trainees, who will build knowledge, lively and distantly, individually and in teams, in conjunction with the scientific and local communities, with schools open to society, in interaction and for mutual benefit. The European 'Structural Reform Support Programme' (SRSP, 2016) draws on positive experiences with technical assistance in connection with reforms in Greece and Cyprus and aims to make the expertise gathered available to all Member States, on a voluntary basis and at the Member State's request.

The training provided by the New School Action Plan (NSSD, 2010) was aimed at empowering and empowering the teachers to make use of the possibilities offering by the constant evolution of ICTs, to facilitate and upgrade the quality of their work. It focused on the subject of science, pedagogical methods, new technologies, and education management. The relevant Training Programs include Core Seminar, Distance Learning, and the Feedback Seminar. This targeted and large-scale training could gradually give way to other forms of training, and mainly encourage the in-school training, based on the needs of small groups or individual school units. The political changes, stopped the educational reforming and the implementation of the Major Training Program which accompanied the New School Action Plan.

\subsubsection{Programs of Teacher Training}

As previously has referred, there is a few data about the effectiveness of Teachers' Training in Greece during the past half century and this is fragmentary and not always formally documented and easily accessible by stakeholders. The following information provides an indication about the content of training during the first three years of the RTCs' operation, in 1992-1995, as had reported in Eurydice (ED, 1995). The 'Introductory' training focused generally on theory and practice of education, structure and organization of the education system, general issues and current problems, education and psychology, teaching methods, practical exercises. The 'Periodic' training was at a more advanced level. 'Special' in-service training programs offered in the fields of philosophy of education, sociology of education, educational theory, psychology, special teaching, and teaching practice in schools. During the last 25 years, voluntary training developed in the fields of theory and practice of education, the organization and administration of education, scientific and educational guidance for teachers. 
There were also short seminars on various, specific subjects.

\section{Teacher Training by the Office of Secondary Education}

The Teacher Training Office in Secondary Education of the Greek Ministry of Education and Religious Affairs was responsible for the planning and implementation of training programs in the decade 1999-2009 (DSDE, 2009). On the website of the Greek Ministry of Education uploaded the following information about the training programs that the Ministry had implemented for the Secondary Teachers in Greece (YPPAITH, 2009): A. Updating of teachers who have been serving on the developments of science and new teaching and assessing methods, to develop their capacity to respond to changing conditions of education and effectively carry out their work, B. Informing teachers on important educational issues with new subjects. According to the same report, the training programs were divided into three types:

A. Semester (six-month) and long (annual) training to educate teachers about science progress, education policy, renewal of teaching and assessment methods, and more general training for more effective exercise of their work.

B. Periodic compulsory education for teachers, which takes place during the academic year at a regional or national level when it comes to changing school programs and introducing new courses, new teaching methods and school books.

C. Periodic optional training in the various Regional Training Centers (RTCs).

These programs referred to various themes so that the teachers and aimed:

- To be informed of developments in specific scientific, pedagogical, technological, social, political and economic areas directly linked to their specialties and work.

- To acquire the appropriate methodological tools to better understand and critically address developments that will lead them to informed choices, better organization and more effective reformation of their educational work.

- To be informed about issues related to school life, such as organization and school management, dynamics, problems and management of the student community, problem situations management, multicultural compositions, etc.

- Teachers of the Technical and Vocational Education to renew their pedagogical and technical knowledge, as require the rapid development of technology and the resulting changes in the labor market.

- To sensitize learners and to promote their lifelong learning to improve their professional qualifications

- To familiarize themselves with the use of PCs and multimedia, with the use of European programs, with the development of advisory services/mechanisms in the school unit etc.

According to the uploaded information in the same website, the following training programs had been carried out, in the period 1999 to 2009, for the teachers of Secondary Education all over Greece (DSDE, 2009): A. Short Term Compulsory Training Programs: 1. Fast-paced 
Compulsory Education Programs for seven teachers' specialties, permanent teachers in the Unified Lyceum and substitute on new school books during September-October 1999, 2. An Educational Workshop in 2000 addressed to School Advisors of Primary and Secondary Education in order to be informed about the Questionnaire which was distributed in the City of Athens, and involves conducting research aimed at recording and investigating the training needs and priorities of the trainees. B. Accelerated Optional Training Programs: the RTCs of the whole country programmed and implemented, from the beginning of the school year 19992000, up to today 470 fast-track optional training programs lasting 40 hours each, attended by a total of 14.100 trainees of the local educational regions C. Training Programs of Medium and Annual Duration: during the winter semester 1999-2000, the programs of semester duration were held in the various University Departments of the country, attended by 460 trainees of 13 specialties of Secondary Teachers.

During the school year 2000-2001, from December 2000 to June 2001, was implemented the Yearly duration training programs by various University Departments of the country. These programs were of 420 hours and 736 teachers were trained of 14 specialties of private and public Schools.

\section{Teacher Training by the Regional Training Centers (RTCs)}

The RTCs established in 1992 (Law 2009/1992) with the purpose to exploit the governmental policy and extinct the aims and objectives of public education in the way that each government was realizing. In the 1995-96 period, more flexible training took place in the RTCs, with a relaxation of direct control over the program and the teaching staff, but not for the purposes of their implementation. During this period, many short-term and paid out-of-work programs were offered, indicating an increase in the mass of teachers attending those (Karagiannis et al, 2012). RTCs carried out training programs in regions of Greece with the purpose to cover the training needs of all the teachers of Primary and Secondary Education. RTCs had established with the purpose to offer high quality training programs to the teachers of all specialties of Primary and Secondary Education, under the guidance of the Greek Ministry of Education, Research and Religious affairs and the Greek Pedagogical Institute, now Institute of Educational Policy. With the dissemination format of the seminars, training becomes modular, open and decentralized, without geographical disparities, so more effective.

In RTCs also implement Special Education and Training (EAE) training programs for teachers of various disciplines on both levels of Education, setting out their objectives, their overall duration, the subjects to be taught and the thematic units, the number of teachers to attend, the bodies that will implement it, the prerequisites and the process of selecting the trainers, as well as any issue related to the training of the above teachers (Law 3966/2011).

\section{Training in the Field of Environmental Education}

During the last 30 years, the Environmental Education and the Education for the Sustainable Development had much development and offered great possibilities of change in Greek school education. Through the school educational projects, the teachers tried to extend the restrict framework of the traditional curricula in schools by entering the interdisciplinary approaches 
of the teaching cognitive objects and modern methodologies in approaching notions and procedures. The Environmental Education became the vehicle of Change in the School Education from 1995 to 2010, after then it has been slowed down. The teaching, and consequently the training targets, were specified also on the psychomotor sector, not only the cognitive with negotiated subjects on Ecology, team work and cultivation of creativity and innovation. All the set targets were supported with a large number of training seminars, workshops, congresses converging to cultivate teachers' walking with innovation in their lifelong learning and professional procedure. The seminars organized, mainly, by the Centers of Environmental Education, Universities, other Bodies, and the Heads of the Offices of Environmental Education in the Administrations of Primary and Secondary Education in each prefecture of Greece. The trainees were teachers who had the pedagogical guidance and coordination of school educational projects in those periods. In this way, the school educational projects became in-school training programs for the teachers of all specialties. The inquiry based learning and the outdoor education emerged as revolution need to evolve the curricula, the courses, the learning environment, the routine of the everyday school life for students and teachers. In this way, the schools opened to the local communities, the local Authorities incorporating the support of educational interventions of schools in connection to the society, into their strategic plans. In this way, the lifelong learning had been borne through the intergeneric communication for a sustainable future of the school and local communities in Greece (Kalathaki, 2016).

Teachers, with or without students, by participating in the European Projects Comenius, Erasmus, etc. and in National Programs of Environmental Education, Health, Culture, professional guidance etc., received self-training, in-school training with their pace, in the subjects they chose with the persons and bodies they collaborated. In this way, the involved teachers tried the changes in Education targets and methodology, in the last 25 years. In line with the United Nations 2030 Sustainable Development Goals, the Erasmus+ programme contributes to a greener, equitable and fair society. Europe can continue to grow and improve in sustainable way, ensuring that all citizens can enjoy prosperous and fulfilling lives and that economic, social and technological progress occurs in harmony with nature, a world with universal literacy, a world in which every country enjoys sustained and inclusive economic growth and decent work for all (UN, 2015).

\subsubsection{Assessment of Teachers' Training in Greece}

In Eurydice (1995) report is referred that the Greek in-service training institutions are not usually systematically assessed. The assessment sometimes takes the form of visits by inspectors or by external assessment teams. The authorities responsible for in-service training have not yet, established a general strategy for assessing the in-service training system. Training courses are more easily assessed by means of questionnaires distributed to the participants, the usual way of evaluation in RTCs (ED, 1995). Also, it is difficult to associate voluntary participation with assessment if this term implies testing. Presidential Decree (PD) $152 / 2013$ provided criteria for the evaluation of the teaching staff of Primary and Secondary Education of Greece, but political forces stopped it in its first period of application, so there isn't any data on the profile of teachers and the lack of knowledge, abilities and skills that they 
have in order to be prepared appropriate training programs to improve the effectiveness of their educational work. The essential evaluation is therefore self-assessment, formal attestation taking the form of a certificate of attendance and participation. Approaches to all these issues of quality assessment are extremely diverse, ranging from attempts to interrelate analysis of needs, formulation of expectations and appraisal of results, to a feeling that nothing which happens during in-service training can be assessed because it concerns the personal development of individuals (ED, 1995). Sometimes a questionnaire allows the participants to gauge what they have gained from the training sessions in relation to their initial expectations.

In the survey of the Greek Pedagogic Institute, in 2010, which investigated the training needs and priorities of the Greek Teachers, only $16 \%$ of the total serve in Primary and Secondary Education) positively evaluated the training programs that they had attended, with minor variations by Region, Level and Specialty, in terms of content, methodology and organizing. Analysis of the data, in terms of imprinting by its teachers importance of incentives to participate in a program training (motivation for the professional development of the teacher), "Certification of training" was the first choice of teachers to $56,13 \%$, followed by the Financial Aid (52,24\%) and the Greek Government Grading (44.81\%). Regarding the time period of the training program, they chose within school hours in a percentage $56.5 \%$, followed by a significant difference in pre - and post -end of school year with 31,11\% and out of school hours at $22.39 \%$ (MPE, 2010). The objective of the 'Structural Reform Support Programme' is to offer technical assistance to all Member States, aimed at improving their institutional and administrative capacities for implementing structural reforms with a view to building strong economic foundations (SRSP, 2016). Eligible actions of the Programme include workshops, expert advice, working visits, training, data collection, research, methodology development, IT capacity building, studies, evaluations and awareness-raising campaigns, systems and tools. This program is expecting to support the teacher training policy in Greece as it happened with the previous developmental project which funded the New School Action Plan (NSSD, 2010).

Over the past 20 years, large funding from the Greek State, CSF and the NSRF have been used to train teachers, but not always in the most effective way, as the professional development of the teacher has not been materially linked to the existing forms of training. In so many educational reforms that tried in Greece, many changes in the school curricula and teaching methodologies have been introduced to support theses reformative policies. Many times, training had been done either to absorb some money or just to acquire formal, above all, qualifications. Also, often, the various forms of training are implemented without any coordination and no synergy, as is widely discussed in teacher community and Mpagakis (2012) referred. They attribute the reasons of the ineffectiveness to the central designing and coordination of multiple, often scattered and unknown forms of training, as the main reason, with the ways of guidance and funding of the EU and the Teacher Training Organization (OEPEK) was established.

\subsection{For a Sustainable Future...}

The schools that try to transform the lessons of the traditional curricula into events of design, learning \& innovation have to take into consideration cutting-edge research in the field of art 
and technology related to interactivity, such as augmented reality, virtual reality, game creation as well as results from research into tools, technologies, methodologies and innovative solutions for education. Schools have to clarify and determine the needs that they meet, in terms of quality development and internationalization, which will be the main areas for improvement, for example staff management competences, new teaching methods and techniques, European dimension, language competences, curricula, mobility, in general, the organization of teaching and learning in a new, modern way and attractive working environment (SEC, 2007; SEC, 2008). Head-teacher training should be designed as a continuum starting with initial teacher training and leading to a gradual diversification of functions, taking account of the individual's wishes and aptitudes. This implies that the design of teacher training should not be isolated from that of management staff (UNESCO, 2006).

The schools, as educational and simultaneously in-school training organizations develop and integrate the competences and experiences acquired by staff participating in the school education projects of Environmental Education and any lifelong learning programs, for personal and institutional strategic development (Erasmus KA2 2016 application form). The Erasmus + program can support Europe to continue to grow and improve in a viable way, and through education, training and volunteerism to ensure a sustainable economy for the good of the next generations (BG, 2014).

Rather than being the exception, as is the case today, learning mobility can become a natural feature of Europeans and a possibility open to all young people in Europe. In doing so, it can make a significant contribution to ensuring the future competitiveness and cohesion of the European Union. Learning mobility can develop a deeper awareness of European identity and citizenship among young people. It also accelerates the dissemination of knowledge, which is a key element in the knowledge-based Europe's future (COM, 2009).

\subsubsection{The Cultivation of Creativity and Innovation}

The cultivation of creativity has been written thousands times in million educational projects in the last 30 years all over the word. Also, 2009 thematic year of the European Union was dedicated to Innovation and Creativity (EC, 2009; EC, 2010; EU, 2008). All these projects tried to achieve the target of innovation with creativity with great variety of methodologies, techniques, tools, with the support of many individuals and bodies, exploring abundant natural and human resources. In the report on a new skills agenda, European Council recalls that the creative industries are among the most business and fast-growing sectors and creative education fosters transferable skills such as creative thinking, problem solving, teamwork and resourcefulness recognizes that the arts and media sectors particularly attract young people's interest (PDECP, 2015; EP, 2017). But, as Sir Ken Robinson in TED says that the school kills the creativity, we need a new direction in changing education, to manage the talent, since life is our talents' discovering. There is urgent need, the new curricula to incorporate the skills that students need for their future, and, if creativity can be taught, the art of teaching has to build a culture of innovation out of our minds, with educating the heart and mind. Teachers will shoulder the learning revolution to escape from the education matrix, as Francis Gilbert told (FS, 2017). 
The importance of innovation policy is widely recognized. It is also strongly linked to other EU policies, such as those on employment, competitiveness, environment, industry and energy. The role of innovation is to turn research results into new and better services and products in order to remain competitive in the global marketplace and improve the quality of life of Europe's citizens. Innovation policy is the interface between research and technological development policy and industrial policy and aims to create a conducive framework for bringing ideas to market (FS, 2017). A remarkable brain drain has been noticed in many European countries, mostly in those affected more by the economic crisis, and occurs as best researchers and innovators move to countries where conditions are more favorable (Euro2day, 2016).

The Commission calls on the Member States not only to focus on employability skills, literacy, numeracy, digital literacy and media literacy, but also on skills that are generally relevant to society, along with the strengthening of European craft industry, recalls that investing in the capacity of education today will determine the quality of jobs now and in the future, the skills of workers, social well-being and democratic participation in society (EP, 2017).

\subsubsection{Entrepreneurship in Education}

Development is at the heart of the European Union's internal and external policies where emphasizes the need to integrate business learning data, including social entrepreneurship, into all levels of education and in various courses. It can foster entrepreneurship among young people at an early stage, to increase employability and help fight youth unemployment. The new curricula can contribute to this direction by encouraging creativity, critical thinking and leadership skills that are useful for implementing social projects in local communities, also by drawing lessons from the experience and the concept of the positive failure (EP, 2017). The reality in Greece of today records a very high youth unemployment rate in Europe, low youth entrepreneurship rates and the migration of a skilled workforce. An important measure for reducing youth unemployment is to strengthen their employability, which can be achieved primarily by consolidating the framework of the requirements of modern economic and business reality. Since entrepreneurial activity is shifting to the 50+ age group, strengthening business skills in juvenile groups is a challenge and a field with great potential for exploitation.

Though all students have their own knowledge since beginning, most knowledge is scattered, and the students cannot understand how to apply the scattered knowledge into practice, especially under various contexts. A research on Youth Education \& Entrepreneurship which carried out by the EU focused on the development of entrepreneurial learning for young people aged approximately 13-19 years who attend Secondary Education schools or colleges. It seeks to address three questions: $\mathrm{a}$. is entrepreneurship treated as a key competence at school? $\mathrm{b}$. how open are schools to "incursion" from the "business world"? c. have there been any "revolutions" in the education/training system? If so, how far have those fundamental changes gone? The methodology adopted comprised the identification and analysis of secondary sources of bibliographic information (Chell, 2015). The research approached the entrepreneurship as a process going beyond the identification and teaching of competences, showing where knowledge acquisition, attitudes and intentions development, are fundamental to the process 
of entrepreneurship and the expression of entrepreneurial behavior and outcomes.

Macroeconomic analysis reports show that the combination of a dual education and training system with active labor market policies has the best results. Member States and social partners of Europe have to strengthen the European cooperation in VET, with planning and implementation of targeted policies that will be accessible to everyone, and will provide skills and qualifications on working life and life labor market. It is great challenge to build a bridge for communication between the market work and education and training. Learning outcomes are essential condition even there are differences in collaboration culture in various sections of the educational system (LEC, 2000; Zachilas, 2016).

\section{Epilogue}

In the current decade, we need to check whether achieved consistency in providing education and training for individual citizens via close links to employment policy and social policy, cultural policy, the innovation policy and other policies, affect young people and cooperation with the social partners and other stakeholders (SEC, 2008).

As our professional life evolves, some jobs are lost, others are being created and some, that are not present today, is sure, that they'll become sought after. Changes are not waiting for us, they happen and they are overtaking us before they are well understood. The ageing of teachers is an alarming trend in European countries. As they retired, there is an increasing risk of loss of experience and staff shortages. Innovative recruitment, attractive working conditions, and retention policies can create the new generation of teaching professionals. Developing the competences of teaching staff, including those who have been in the profession for a long time, is also an ongoing and increasingly urgent priority throughout the EU (COM-6, 2016).

Youth Education and Training is the investment of the societies for the future. Teaching in Schools with creativity and innovation is national and European strategy, of high significance and importance, targeting to the economic progress of the local societies. European Union, in accordance to the international academic trends, direct the transformation and reconstruction of curricula and teaching methodologies from the traditional of teacher-centered lessons to student-centered learning events. There is the need, the people of Research, Education, and Training to cooperate locally, think and work globally in order to cultivate the future science, environmental, digital literate students. Executives of the three levels of Education, Research Institutes, Governing Bodies, Organizations and Companies who invest to the future of the young people, coming from various fields of the social life, from Education, Training, Research, Entrepreneurship, Governance and Policy, to undertake initiatives and design plans in a peer learning interchange and sharing of knowledge, experience, wisdom and visions for the future of Greece, Europe, the World widely.

\section{References}

Bell, J. (1997). Methodological Planning of Pedagogy and Social Research. Gutenberg Publications, Athens

BG. (2014). Beginner's guide on EU funding Budget, Overview of EU funding opportunities 
2014-2020, 2014 edition. European Union. https://doi.org/10.2761/883638

Bird, M. (1990). The implementation of educational policy: a case study of the implementation of the Open College of South London (Thesis, University of London).

Chell, E. (2015). Youth Education \& Entrepreneurship, Directorate-general for internal policies, Policy department B, structural and cohesion policies, Culture and Education, workshop documentation. Retrieved from http://www.europarl.europa.eu/studies

COM. (2009). Green Paper - Promoting learning mobility for young people, Commission of the European Communities Brussels, 8.7.2009.

COM-6. (2016). A New Skills Agenda for Europe, Communication from the Commission to the European Parliament, the Council, the European Economic and Social Committee and the Committee of the Regions, Working together to strengthen human capital, employability and competitiveness, $\{\operatorname{SWD}(2016) 195$ final $\}$, Brussels, 10.6.2016COM(2016)381

Dimitropoulos, E. (1999). Educational Assessment, Part I, Evaluation of Education and Educational Project (5th ed.). Gregori Publishing, Athens.

DSDE. (2009). Teacher Training in Secondary Education, Greek Ministry of Education and Religious Affairs. Retrieved from http://www.ypepth.gr/el_ec_pagesst1045.htm

EC. (2009). Consultation on the Future "EU 2020" Strategy, Commission Working Document, Commission of the European Communities, Brussels, 24.11.2009, COM(2009)647 final.

EC. (2010). EUROPE 2020: A strategy for smart, sustainable and inclusive growth, European Commission, Brussels, 3.3.2010, COM(2010) 2020 final.

ED. (1995). Teacher training in the European Union and the EFTA/EEA Countries, EURYDICE, The Education Information Network in the European Union and the EFTA/EEA Countries ISBN 2-87116-224-7, EURYDICE European Unit, Brussels.

EP. (2017). Report on a new Skills Skill for Europe (2017/2002 (INI)), Committee on Employment and Social Affairs Committee on Culture and Education, Rapporteurs: Martina Dlabajová, Momchil Nekov, European Parliament. Retrieved from http://www.europarl.europa.eu/sides/getDoc.do?pubRef=-\%2F\%2FEP\%2F\%2FTEXT\% 2BREPORT\%2BA8-20170276\%2B0\%2BDOC\%2BXML\%2BV0\%2F\%2FEL\&language $=\mathrm{EL}$

EU. (2008). EUROPE 2020 Delivering lifelong learning for knowledge, creativity and innovation pages 17-23 joint progress report of the Council and the Commission on the implementation of the "Education \& Training 2010 Work Programme". Retrieved from http://ec.europa.eu/education/lifelong-learning-policy/doc/natreport08/council_en.pdf

Europe 2020. (2010). A strategy for smart, sustainable and inclusive growth, Communication from the European Commission, Brussels, 3.3.2010, COM(2010) 2020.

Euro2day. (2016). Europe's goodbye to scientists Posted on 12/3/2016 on the website Source: 
Premium. Retrieved from http://www.euro2day.gr/news/world/article/1405612/ shkonoyn-pania-oi-evropaioi-episthmones.html

FS. (2017). Innovation policy, Fact Sheets on the European Union, European Parliament. Retrieved from http://www.europarl.europa.eu/atyourservice/en/displayFtu.html?ftuId= FTU_2.4.6.html

HM-PL. (2017). New Structures in Education and the Institution of the School Advisor, Framework of the Workshop, Co-organizing of Regional Training Center of Piraeus and University of Peloponnese, Ionian School of Piraeus, 16 December 2017.

Kalathaki, M. (2016). Education for the Sustainable Development: International Strategies and the Greek Experience in Secondary Education. Asian Academic Research Journal of Social Science \& Humanities, 3(5). Retrieved from http://www.asianacademic research.org/2016_abstract/may2016/20.pdf

Karagiannis, G., Stagia, P., \& Circus, M. (2012). The role of the teacher in the historical course of education. Retrieved from http://www.elemedu.upatras.gr/eriande/synedria/ synedrio3/praltika\%2011/karagiannis

LEC. (2000). Lisbon European Council, Presidency Conclusions, Lisbon European Council 23 and 24 March 2000. Retrieved fom http://www.europarl.europa.eu/summits/ lis1_en.htm

Mpagakis, C. (2012). Institutional and new forms of training-To seek synergy and good practices, OEPEK, Operational Program "Education and Lifelong Learning".

MPE. (2010). Contribution of Investigating Training Needs in Teacher Training: A Comparative Interpretation of Results, Major Program of Training. Retrieved from http://www.epimorfosi.edu.gr/images/stories/e-books/ap_anagk/pdf/8_sysxetisi.pdf

NSSD. (2010). 'The New School: First the Student'-The Action Plan. Retrieved from http://pischools.gr

PDECP. (2015). The impact of the crisis on skills shortages, study for the EMPL Committee Policy Department Economic and Scientific Policy, Proceedings of the Workshop on The impact of the crisis on skills shortages, Brussels, 23 March 2015, European Parliament, B-1047 Brussels (2015), Retrieved from www.europarl.europa.eu/studies

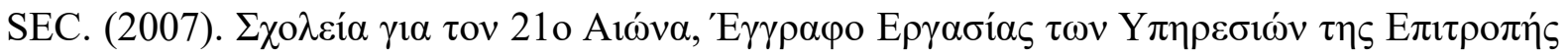

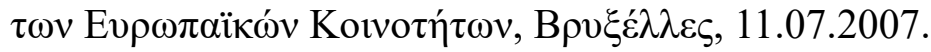

SEC. (2008). Key messages to the Spring European Council in the fields of Education/Training and Youth, Report from the Council (Education, Youth and Culture) to European Council (Brussels 20 February $2008 \quad$ (26.02) 6445/08. Retrieved from http://register.consilium.europa.eu/doc/srv?1=EL\&f=ST\%206445\%202008\%20INIT

SRSP. (2016). Structural Reform Support Programme 2017-2020, Briefing, October 2016, European Parliament EPRS | European Parliamentary Research Service, Author: Agnieszka Widuto, Members' Research Service PE 593.495 
UN. (2015). Education 2030 Incheon Declaration and Framework for Action Towards inclusive and equitable quality education and lifelong learning for all. Retrieved from http://www.unesco.org/new/fileadmin/MULTIMEDIA/HQ/ED/ED_new/pdf/FFA-ENG27Oct15.pdf

UNESCO. (2006). The New Roles of Secondary School Head-teachers, UNESCO Interagency Group on Secondary Education, Section for General Secondary Education.Retrieved from http://unesdoc.unesco.org/images/0014/001490/149057e.pdf

YPPAITH (2009) Training Programs of Secondary Education, Office of Secondary Education of the Greek Ministry of Education \& Religious Affairs

Zachilas, L. (2016). European policies for vocational education and training, DSI Head of Sector, CEDEFOP, Thessaloniki December 10, 2016.

\section{Copyright Disclaimer}

Copyright reserved by the author(s).

This article is an open-access article distributed under the terms and conditions of the Creative Commons Attribution license (http://creativecommons.org/licenses/by/3.0/). 